\title{
Lung function in children in relation to ethnicity, physique and socioeconomic factors
}

\author{
Sooky Lum ${ }^{1}$, Vassiliki Bountziouka ${ }^{1}$, Samatha Sonnappa ${ }^{1,2}$, Angie Wade ${ }^{3}$, \\ Tim J. Cole ${ }^{3}$, Seeromanie Harding ${ }^{4}$, Jonathan C.K. Wells ${ }^{3}$, Chris Griffiths $^{5}$, \\ Philip Treleaven ${ }^{6}$, Rachel Bonner ${ }^{1}$, Jane Kirkby ${ }^{1,7}$, Simon Lee ${ }^{1}$, \\ Emma Raywood ${ }^{1}$, Sarah Legg ${ }^{1}$, Dave Sears ${ }^{1}$, Philippa Cottam ${ }^{1}$, \\ Colin Feyeraband ${ }^{8}$ and Janet Stocks ${ }^{1}$
}

\begin{abstract}
Affiliations: ${ }^{1}$ Respiratory, Critical Care \& Anaesthesia Section in IIIP Programme, UCL Institute of Child Health, London, UK. ${ }^{2}$ UCL Institute of Global Health, London, UK. ${ }^{3}$ Population, Policy and Practice Programme, UCL Institute of Child Health, London, UK. ${ }^{4}$ MRC Social and Public Health Sciences Unit, University of Glasgow, Glasgow, UK. ${ }^{5}$ Asthma UK Centre for Applied Research, Blizard Institute - Queen Mary University of London, London, UK. ${ }^{6}$ Dept of Computer Science, UCL, London, UK. ${ }^{7}$ Great Ormond Street Hospital for Children NHS Foundation Trust, London, UK. ${ }^{8}$ ABS Laboratories, Welwyn Garden City, UK.
\end{abstract}

Correspondence: Sooky Lum, Respiratory, Critical Care \& Anaesthesia Section in IIIP Programme, UCL, Institute of Child Health, 30 Guilford Street, London WC1N 1EH, UK. E-mail: s.lumaucl.ac.uk

ABSTRACT Can ethnic differences in spirometry be attributed to differences in physique and socioeconomic factors?

Assessments were undertaken in 2171 London primary schoolchildren on two occasions 1 year apart, whenever possible, as part of the Size and Lung function In Children (SLIC) study. Measurements included spirometry, detailed anthropometry, three-dimensional photonic scanning for regional body shape, body composition, information on ethnic ancestry, birth and respiratory history, socioeconomic circumstances, and tobacco smoke exposure.

Technically acceptable spirometry was obtained from 1901 children (mean (range) age 8.3 (5.2-11.8) years, $46 \%$ boys, 35\% White, 29\% Black-African origin, 24\% South-Asian, 12\% Other/mixed) on 2767 test occasions. After adjusting for sex, age and height, forced expiratory volume in $1 \mathrm{~s}$ was $1.32,0.89$ and 0.51 z-score units lower in Black-African origin, South-Asian and Other/mixed ethnicity children, respectively, when compared with White children, with similar decrements for forced vital capacity $(\mathrm{p}<0.001$ for all). Although further adjustment for sitting height and chest width reduced differences attributable to ethnicity by up to $16 \%$, significant differences persisted after adjusting for all potential determinants, including socioeconomic circumstances.

Ethnic differences in spirometric lung function persist despite adjusting for a wide range of potential determinants, including body physique and socioeconomic circumstances, emphasising the need to use ethnic-specific equations when interpreting results.

@ERSpublications

Ethnic differences in spirometry cannot simply be attributed to differences in physique and socioeconomic factors http://ow.ly/R8EaR

This article has supplementary material available from erj.ersjournals.com

Received: March 132015 | Accepted after revision: July 142015 | First published online: Oct 222015

Support statement: This work was supported by the Wellcome Trust (WT094129MA), Asthma UK (10/013) and the Child Growth Foundation. T.J. Cole is funded by MRC research grant MR/J004839/1. The SLIC (Size and Lung function In Children) study team acknowledges the support of the National Institute for Health Research, through the Comprehensive Clinical Research Network. Funding information for this article has been deposited with FundRef.

Conflict of interest: Disclosures can be found alongside the online version of this article at erj.ersjournals.com

Copyright OERS 2015 


\section{Introduction}

Ethnic differences in lung function are well documented and the importance of adjusting for ethnicity has been emphasised [1-6]. However, the paucity of spirometry references taking ethnicity into account, especially in children, impedes diagnosis and clinical management of lung disease, and complicates interpretation of clinical trials where lung function is a primary outcome [6]. The recently published Global Lung Function Initiative (GLI)-2012 multiethnic spirometry equations [7] provide a good fit for contemporary Black-African origin and White London primary schoolchildren [8], and although the published equations did not cover all ethnic groups, a preliminary coefficient for South-Asian children based on GLI-2012 has been developed $[9,10]$. Nevertheless, ascribing ethnicity is complicated in an increasingly multiethnic society.

Standing height is a major determinant of lung function, but differences in body proportions and composition may explain much of the remaining ethnic variation. Despite long-standing attempts to identify factors underlying ethnic differences in lung function $[1,3,4]$ the contribution of body physique is not well understood. Identification of the best linear measurements to explain variability in lung function is complicated by the large number of such measurements and the impracticality of obtaining them, especially in children. Whole-body three-dimensional (3D ) photonic scanning, a new technology that provides rapid, detailed data on regional body shape from digital anthropometry, could address such issues [11].

The extent to which ethnic differences in lung function are associated with genetic ancestry as opposed to environmental exposures, nutritional or socioeconomic circumstances also remains controversial $[1,3,12,13]$, with interpretation compromised by the paucity of appropriate high-quality data. Although some groups have suggested that the same ventilatory function predicts the same level of mortality in different ethnic groups, thus discouraging the use of ethnic-specific equations [14], others have reported that African genes are associated with lower lung function [5] and that differences in socioeconomic circumstances explain only a small proportion of ethnic differences [3, 15-17].

The primary aim of this study was to ascertain the extent to which ethnic differences in lung function can be attributed to differences in physique and socioeconomic factors. Secondary aims were to identify simple measures of physique (in addition to standing height) that could be used in a clinical setting to improve prediction of lung function and to confirm that the GLI-2012 equations are appropriate for a multiethnic population of London schoolchildren.

We hypothesised that after adjusting for sex, age and standing height, inclusion of additional measures of body physique and socioeconomic factors would significantly reduce ethnic differences in lung function by at least 50\%. Prior to undertaking analyses for this study, methodology relating to selection of the reference population [18], categorising birth [19] and pubertal [20] status, 3D assessments [21], and body composition [22] were explored, and new GLI coefficients for interpreting spirometry from South-Asians were derived [9].

\section{Materials and methods}

The Size and Lung function In Children (SLIC) study was a prospective study designed to assess spirometry, and body size, shape and composition in a population of multiethnic children (5-11 years) in London schools. Following a pilot study (see online supplementary material section 1.1), children were recruited between October 2011-July 2013 by taking home recruitment packs for parental consent to participate (see online supplementary section 1.2). All children with parental consent were eligible, although data from those with current and chronic lung disease (e.g. sickle cell disease, cystic fibrosis, current asthma/wheeze) or significant congenital abnormalities were excluded from analysis [18]. Children were sampled in alternate year groups, with spirometry and full assessments of body physique obtained during the first year of data collection in 5-, 7- and 9-year-old children, and spirometry plus routine measures of body shape and composition obtained when possible the following year in 6-, 8- and 10-year-old children. The study was guided by a Steering Committee and approved by the London-Hampstead research ethics committee (REC:10/H0720/53). Parental written consent and child verbal assent were obtained prior to assessments.

The study protocol has been published previously [23]. To summarise, during the first year anthropometry included a 3D photonic scan (based on light technology; online supplementary section 1.3), standing height and weight, and manual anthropometry including chest and waist dimensions, mid-arm circumference, knee girth, calf circumference, and foot length (online supplementary table E1) [23]. At the end of year 1, interim analysis of the 3D data identified the best linear measures for predicting lung function and manual anthropometry in year 2 was restricted to these measures (see online supplementary section 2.1).

Body composition was assessed using bioelectrical impedance analysis, with paired measurements of total body water by deuterium dilution in a subsample of 607 children, in order to derive ethnic-specific calibration equations to predict fat-free mass [22]. Spirometry was performed to standard protocols using European Respiratory Society/American Thoracic Society acceptability and repeatability criteria, adapted for children where appropriate [24]. A parental questionnaire provided details regarding ethnicity 
(including birth country for child, parents and grandparents), birth status, health, pubertal status and socioeconomic circumstances, assessed at individual level with the Family Affluence Score (FAS) [25] and receipt of free school meals, and at area level with the English Index of Multiple Deprivation (IMD) score based on home postcode [26]. Saliva samples were collected for cotinine analysis to validate parentally reported tobacco smoke exposure (ABS Laboratory Ltd, Welwyn Garden City, UK) (online supplementary section 1.4). Additional consent was sought to contact the child's general practitioner (GP) to supplement information on respiratory health and birth data (online supplementary section 2.2 and table E3) [19]. However, due to the low retrieval of data from GPs compared with parents (22\% versus 95\%), analysis using birth data was based on parental questionnaires [19].

Based on parental report, children were broadly categorised as: White (European ancestry), Black-African origin (African or Caribbean descent); South-Asian (Indian, Pakistani, Bangladeshi or Sri Lankan descent) and children of Other/mixed ethnicities (online supplementary section 3).

Data management and statistical analysis

See online supplementary section 2 for details.

\section{Interim analysis}

Height, age and sex, the major determinants of lung function [7], were used in the interim base model. As height cannot be measured from 3D scans [21], models were initially developed using manual anthropometry and subsequently confirmed using 3D data. On univariable analysis, after adjustment for sex, age and height, most anthropometric measures were significantly associated with forced expiratory volume in $1 \mathrm{~s}(\mathrm{FEV} 1)$ and forced vital capacity (FVC) (online supplementary table E2). However, on multivariable analysis, only sitting height and chest dimensions (width, depth and circumference) remained associated with FEV1 and FVC (online supplementary figure E2). Results were similar with 3D data. Consequently, manual assessments in year 2 were limited to chest dimensions, sitting height, standing height and weight (online supplementary table E1).

To emphasise clinical application and express the magnitude of ethnic differences in relation to White children, final analysis was based on lung function z-scores for White children [7], together with height and weight z-scores using the British 1990 growth reference [27]. With lung function z-scores as the outcomes, the base model included age, sex and log height to balance the GLI-2012 adjustments. Sitting height and then the three chest dimensions (all log-transformed to allow for allometric scaling) were then added to the model (online supplementary table E6). Models were compared using the Bayesian information criterion (BIC) [28]; a smaller BIC indicating a better fit. The additional contributions of lean mass and socioeconomic circumstances (quintiles of IMD or categories of FAS) to the best model were also tested, as were interactions between ethnicity and anthropometry or socioeconomic circumstances. The two-tailed significance level was set at 0.05. The "nlme" package in R (version 3.1.0) was used to account for individual clustering [29].

To ascertain the appropriateness of the GLI equations for multiethnic schoolchildren, lung function results were also expressed as ethnic-specific z-scores [7], those for South-Asian children being based on a preliminary GLI coefficient derived for this group [9, 10]. One-way analysis of variance was used to assess differences in lung function and growth between ethnic groups and FAS categories.

\section{Results}

In total, 2171 children (mean (range) age 8.2 (5.2-11.8) years, 47\% boys; 34\% White; 29\% Black-African origin, 25\% South-Asian, 12\% Other/mixed ethnicity) participated. After exclusions, data from 1901 children (mean \pm SD age $8.3 \pm 1.6$ years, $46 \%$ boys) on 2767 test occasions were included (hereafter referred to as the reference population; figure 1) [18].

Sex and age were distributed similarly across the ethnic groups (Table 1 and online supplementary table E5). On average, $6 \%$ of children were born preterm ( $<37$ weeks gestation) and $7 \%$ were low birthweight $(<2.5 \mathrm{~kg})$, the latter disproportionately South-Asian. Prior wheeze and current symptoms were relatively uncommon ( $9 \%$ and $7 \%$, respectively), although $13 \%$ of Other/mixed ethnicity children reported previous asthma. According to parental report, $18 \%$ of children above 8 years of age had started puberty [20].

\section{Ethnic differences in body physique}

Adjusted for age and sex, Black-African origin children were significantly heavier and taller with longer legs than children from other ethnic groups (table 2 and online supplementary table E5). Adjusted for sex, age and height, chest circumference was significantly larger and ratio of chest depth/width significantly higher in Black-African origin than White children, but chest area did not differ. Compared with White children, after adjusting for sex, age and height, fat-free mass was on average higher in Black-African 


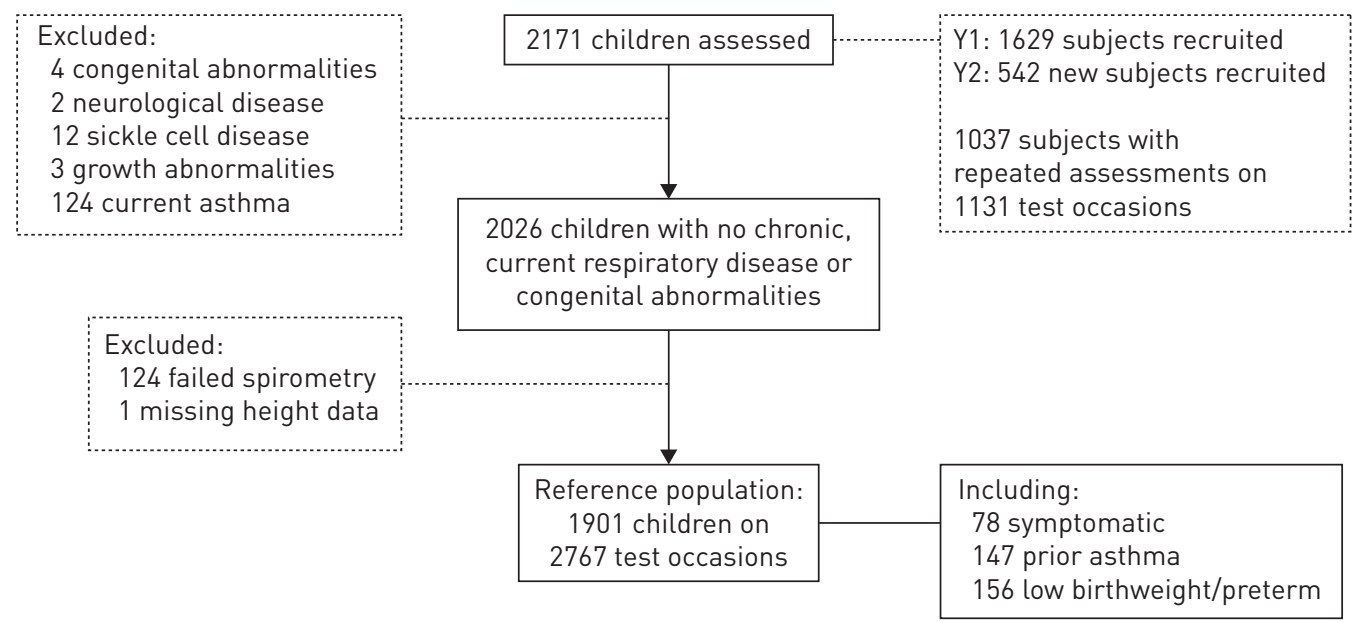

FIGURE 1 Children participating in the Size and Lung function In Children (SLIC) study. Data from 82 children recruited from the pilot study were also included in the analysis. Not all children recruited in year 1 participated in the follow-up due to having moved schools or no parental consent received, whereas some children who had not been assessed in year 1 participated in the follow-up. Y1: year 1; Y2: year 2.

origin children (difference $(95 \% \mathrm{CI}) 0.7(0.5-0.9) \mathrm{kg})$, lower in South-Asians $(-1.4(-1.7--1.2) \mathrm{kg})$ and similar in those of Other/mixed ethnicity.

Ethnic differences in socioeconomic circumstances and tobacco smoke exposure

Overall, $27 \%$ of children were receiving free school meals, with Black-African origin children representing the highest proportion (table 1). Similarly, relatively more Black-African origin children scored low on FAS and IMD (table 1 and online supplementary table E4). White and Other/mixed ethnicity children experienced most smoke exposure (table 1). Salivary cotinine levels were $<2.5 \mathrm{ng} \cdot \mathrm{mL}^{-1}$ in $99.7 \%$ of children with no reported household smoking, whereas for cotinine levels $>2.5 \mathrm{ng} \cdot \mathrm{mL}^{-1}$ (range $2.6-10.9 \mathrm{ng} \cdot \mathrm{mL}^{-1}$ indicative of

TABLE 1 Baseline characteristics of the reference population ( $n=1901$ ) on their first test occasion

White $\quad \begin{gathered}\text { Black-African } \\ \text { origin }\end{gathered} \quad$ South-Asian $\quad$ Other/mixed

\begin{tabular}{|c|c|c|c|c|}
\hline Subjects $\mathrm{n}$ & 664 & 543 & 462 & 232 \\
\hline Boys & 48 & 42 & 48 & 45 \\
\hline Age years & $8.2 \pm 1.6$ & $8.3 \pm 1.6$ & $8.3 \pm 1.7$ & $8.3 \pm 1.7$ \\
\hline Born in UK & $87(566 / 654)$ & $86(430 / 502)$ & 79 (357/452) & $90(203 / 226)$ \\
\hline English dominant language & $77(370 / 482)$ & $76(183 / 242)$ & $46(164 / 353)$ & $84(134 / 159)$ \\
\hline \multicolumn{5}{|l|}{ Neonatal characteristics } \\
\hline Low birthweight (<2.5 kg) & 4.4 & 6.6 & 11 & 9.5 \\
\hline Preterm (GA <37 weeks) & 5.0 & 7.0 & 5.8 & 5.6 \\
\hline \multicolumn{5}{|l|}{ Respiratory history } \\
\hline Prior wheeze & $5.8(35 / 602)$ & $8.7(37 / 424)$ & $7.7(31 / 401)$ & $8.1(16 / 197)$ \\
\hline Prior asthma & 7.8 & 9.6 & 5.2 & 12.9 \\
\hline Symptomatic on test day & 6.3 & 5.9 & 6.3 & 3.4 \\
\hline \multicolumn{5}{|l|}{ Socioeconomic circumstances } \\
\hline Receiving free school meals & $19(115 / 608)$ & 53 (198/373) & $12(52 / 430)$ & $32(63 / 198)$ \\
\hline High FAS (5-6): least deprived & $30(190 / 625)$ & $11(49 / 444)$ & $21(95 / 449)$ & $27(57 / 215)$ \\
\hline Low FAS $(0-1)$ : most deprived & $7.2(45 / 625)$ & $15(67 / 444)$ & $8.0(36 / 449)$ & $7.4(16 / 215)$ \\
\hline IMD: least deprived (first quintile) & $11(73 / 657)$ & $0.8(4 / 524)$ & $0(80 / 458)$ & $6.3(14 / 224)$ \\
\hline IMD: most deprived (fifth quintile) & $28(186 / 657)$ & $65(343 / 524)$ & $22(99 / 458)$ & $43(97 / 224)$ \\
\hline \multicolumn{5}{|l|}{ Smoking exposure } \\
\hline Maternal smoking in pregnancy & $7.5(49 / 650)$ & $1.6(8 / 494)$ & $1.8(8 / 451)$ & $7.2(16 / 221)$ \\
\hline Household smoking & $31(175 / 573)$ & $13(49 / 365)$ & $19(68 / 366)$ & $34(67 / 196)$ \\
\hline Child's salivary cotinine (median (25th-75th centile)) $\mathrm{ng} \cdot \mathrm{mL}^{-1}$ & $0(0-0.2)$ & $0(0-0)$ & $0(0-0)$ & $0(0-0.03)$ \\
\hline
\end{tabular}

Data are presented as $\%$, mean $\pm \mathrm{SD}, \%(\mathrm{n} / \mathrm{N})$ or median (25th-75th centile), unless otherwise specified. For variables with missing information, the exact numbers on which the percentages were calculated are shown in parentheses. GA: gestational age; FAS: Family Affluence Scale; IMD: Index of Multiple Deprivation [26]. Details on the selection of the reference population have been reported previously [18]. 
TABLE 2 Anthropometry and lung function according to ethnicity from 2767 test occasions

\begin{tabular}{|c|c|c|c|c|}
\hline & White & $\begin{array}{l}\text { Black-African } \\
\text { origin }\end{array}$ & South-Asian & Other/mixed \\
\hline Subjects n & 664 & 543 & 462 & 232 \\
\hline Test occasions $\mathbf{n}$ & 1000 & 805 & 623 & 339 \\
\hline Age years & $8.5 \pm 1.6$ & $8.6 \pm 1.6$ & $8.5 \pm 1.7$ & $8.5 \pm 1.7$ \\
\hline \multicolumn{5}{|l|}{$\begin{array}{l}\text { z-scores based on British } \\
1990 \text { reference [27] }\end{array}$} \\
\hline Weight & $0.37 \pm 1.0$ & $1.04 \pm 1.1$ & $0.05 \pm 1.3$ & $0.48 \pm 1.2$ \\
\hline Height & $0.30 \pm 1.0$ & $0.93 \pm 1.0$ & $0.14 \pm 1.1$ & $0.36 \pm 1.1$ \\
\hline Sitting/standing height & $0.54 \pm 0.01$ & $0.52 \pm 0.02$ & $0.53 \pm 0.01$ & $0.53 \pm 0.02$ \\
\hline \multicolumn{5}{|c|}{$\begin{array}{l}\text { z-scores based on GLI-2012 } \\
\text { reference (White) [7] }\end{array}$} \\
\hline FEV 1 & $-0.01 \pm 0.9$ & $-1.29 \pm 0.9$ & $-0.88 \pm 0.8$ & $-0.49 \pm 0.9$ \\
\hline FVC & $0.15 \pm 0.8$ & $-1.08 \pm 0.9$ & $-0.80 \pm 0.8$ & $-0.32 \pm 0.9$ \\
\hline FEV $1 / F V C$ & $-0.33 \pm 0.8$ & $-0.43 \pm 1$ & $-0.17 \pm 0.9$ & $-0.34 \pm 0.9$ \\
\hline \multicolumn{5}{|c|}{$\begin{array}{l}\text { z-scores based on GLI-2012 } \\
\text { reference (ethnic-specific) }[7,9]\end{array}$} \\
\hline FEV1 & $-0.01 \pm 0.9$ & $-0.12 \pm 0.9$ & $0.06 \pm 1.0$ & $0.10 \pm 0.9$ \\
\hline FVC & $0.15 \pm 0.8$ & $0.16 \pm 1.0$ & $0.05 \pm 1.0$ & $0.41 \pm 1.0$ \\
\hline $\mathrm{FEV}_{1} / \mathrm{FVC}$ & $-0.33 \pm 0.8$ & $-0.54 \pm 1.0$ & $0.12 \pm 1.0$ & $-0.56 \pm 1.0$ \\
\hline
\end{tabular}

Results are presented as mean $\pm \mathrm{SD}$, derived directly from published equations, unless otherwise stated. GLI: Global Lung Function Initiative; FEV1: forced expiratory volume in 1 s; FVC: forced vital capacity.

passive smoke exposure), 89\% reported household smoking. Cotinine levels (21.1 ng. $\left.\mathrm{mL}^{-1}\right)$ indicative of active smoking [30] were only observed in one 8.7-year-old from a reportedly non-smoking household.

\section{Ethnic differences in lung function}

Based on White GLI-2012 equations, FVC and FEV1 z-scores (mean \pm sD) approximated $0 \pm 1$ in White children, indicating that these equations are appropriate for contemporary White London schoolchildren (table 2$)$. The mean FEV1 z-score was significantly $(p<0.0001)$ lower in all other ethnic groups: -1.32 in Black-African origin, -0.89 in South-Asian and -0.51 in Other/mixed ethnicity children (table 3 ). The pattern was similar for FVC. By contrast, there were no significant ethnic differences in FEV1/FVC. When

TABLE 3 Differences in forced expiratory volume in $1 \mathrm{~s}$ (FEV1) and forced vital capacity (FVC) z-scores (Global Lung Function Initiative (GLI)-White) by ethnicity relative to White subjects, partially and fully adjusted for sex, age and anthropometry from 2751 occasions with full anthropometric data

\begin{tabular}{ccc}
\multicolumn{2}{c}{ Adjusted for } \\
\hline Sex, age, height & $\begin{array}{c}\text { Sex, age, height, } \\
\text { sitting height }\end{array}$ & $\begin{array}{c}\text { Sex, age, height, } \\
\text { sitting height, chest width }\end{array}$
\end{tabular}

\begin{tabular}{lccc}
\hline FEV z-score & & & \\
Black-African origin & $-1.32(-1.4--1.2)$ & $-1.17(-1.3--1.1)$ & $-1.18(-1.3--1.1)$ \\
South-Asian & $-0.89(-1.0--0.8)$ & $-0.77(-0.9--0.7)$ & $-0.76(-0.9--0.7)$ \\
Other/mixed & $-0.51(-0.6--0.4)$ & $-0.46(-0.6--0.3)$ & $-0.47(-0.6--0.3)$ \\
BIC; df & $6277 ; 9$ & $6218 ; 10$ & $6183 ; 11$ \\
FVC z-score & & & \\
Black-African origin & $-1.27(-1.4--1.2)$ & $-1.09(-1.2--1)$ & $-1.11(-1.2--1)$ \\
South-Asian & $-0.95(-1.0--0.9)$ & $-0.80(-0.9--0.7)$ & $-0.80(-0.9--0.7)$ \\
Other/mixed & $-0.47(-0.6--0.3)$ & $-0.42(-0.5--0.3)$ & $-0.43(-0.5--0.3)$ \\
BIC; df & $6188 ; 9$ & $6101 ; 10$ & $5993 ; 11$
\end{tabular}

Data presented as $\beta$-coefficient $(95 \% \mathrm{CI})$, derived from modelling, unless otherwise stated. BIC: Bayesian information criterion; df: degrees of freedom. After further adjusting for sitting height, ethnic differences in FEV 1 and FVC z-scores were further reduced by $11 \%$ and $14 \%$, respectively, in Black-African origin children, by $13 \%$ and $16 \%$, respectively, in South-Asian children and by $10 \%$ and $11 \%$, respectively, in Other/mixed ethnicity children. 
Z-scores were based on the GLI-2012 ethnic-specific equations, FVC and FEV1 z-scores (mean \pm SD) approximated $0 \pm 1$, indicating a good fit, for all but the Other/mixed group, although FEV1/FVC was somewhat lower than predicted among Black-African origin children (table 2).

\section{Contribution of body physique to ethnic differences in lung function}

The best models for both FEV1 and FVC included sitting height and chest width (in addition to age, sex, height and ethnicity) (see online supplementary table E6 for variables included in the modelling). Adjustment for sitting height reduced the differences attributable to ethnicity by $12 \%$ in children of Black-African origin (i.e. from -1.32 to -1.17 z-score units), $13 \%$ in South-Asian children and $8 \%$ in children of Other/mixed ethnicity (table 3 ). Further adjustment for chest width significantly improved the fit $(p<0.0001)$, but did not affect the magnitude of ethnic differences (table 3 ). Results were similar for FVC (table 3). Although fat-free mass contributed significantly to FVC, the coefficients for ethnicity changed negligibly ( $<0.05 \mathrm{z}$-score units). Interactions of lean mass with ethnicity were non-significant.

\section{Contribution of socioeconomic circumstances to ethnic differences in lung function and somatic growth}

The FAS was used to illustrate associations between socioeconomic circumstances, lung function and growth. Although Black-African origin children were taller and heavier than other groups (table 2), no differences between distribution of lung function or growth (adjusted for age and sex) and categories of FAS were observed in any ethnic group ( $p>0.05$, figure 2 and online supplementary figure E4). Socioeconomic circumstances did not contribute significantly, and ethnic differences in FEV1 and FVC changed by $<0.01 \mathrm{z}$-score units $(<0.01 \%)$ when socioeconomic circumstances were included (table 4). Interactions of socioeconomic circumstances by ethnic group were also nonsignificant. Neither maternal smoking during pregnancy nor current exposure to household smoking contributed significantly or had any effect on the ethnicity coefficients.

\section{Discussion}

Based on a large multiethnic population of London schoolchildren, we have demonstrated that after adjusting for sex, age and standing height, when compared with White children, spirometric lung function is lower by $\sim 1.3 \mathrm{z}$-score units (16\% predicted) in children of Black-African origin, $\sim 0.9$ z-score units (10\% predicted) in South-Asian children and $\sim 0.5 \mathrm{z}$-score units ( $6 \%$ predicted) in children of Other/mixed ethnicity. Further adjustment for sitting height reduced these ethnic differences by $10-16 \%$ (table 3). Chest dimensions and lean mass also significantly predict FEV1 and FVC within each ethnic group, but did not affect differences between groups. The persistence of ethnic differences after adjustment for sitting height, chest dimensions, body composition and socioeconomic factors emphasises the importance of taking ethnicity into account when interpreting lung function data. The GLI ethnic-specific equations for FEV1 and FVC provided a good fit for Black-African origin and South-Asian children, but less so for those categorised as Other/mixed ethnicity. Offsets for mean FEV1 and FVC z-scores among Black-African origin children, although small, were in opposite directions, such that mean FEV1/FVC was $0.54 \mathrm{z}$-score units lower than predicted for this group.

\section{Strengths and limitations}

Ours is the largest study to date of lung function, anthropometry and background characteristics in a multiethnic population of schoolchildren aged 5-11 years, demonstrating the feasibility of undertaking a wide range of complex physiological assessments in young children under field conditions. As the association between body mass index and body fatness is affected by ethnicity, we maximised the prediction of body composition in these children using a calibration study [22] to ensure ethnic biases were adjusted adequately. A major strength of the study was that observers were highly trained, and equipment, techniques and quality control were standardised, minimising potential bias. We have previously shown that in a large epidemiological study such as this, inclusion criteria can be relatively inclusive without biasing the results [18]. As the proportions of children with low birthweight, preterm birth, or history of wheeze or asthma were similar across the ethnic groups to that currently reported across England [31] and to other populations of multiethnic inner-city schoolchildren [32], findings from this study should be generalisable.

A potential limitation of this study was that FAS is an asset measure at one time point which may not capture socioeconomic circumstances adequately. We attempted to collect information on parental occupation and education from questionnaires, but these were incomplete. Attempts were also made to collect birth data via health records from GPs in primary care clinics. However, given the low retrieval of data from GPs compared with parents, and the assumption that parents would generally recall details had their child been born preterm or with low birthweight, in this study children with missing birth information were assumed to have been "full term" with appropriate birthweight. While reliance on parental recall regarding birthweight and gestational age may [33] or may not generate bias [34], we found good agreement between parental reports and health records regarding birth status [19]. Categorisation of 


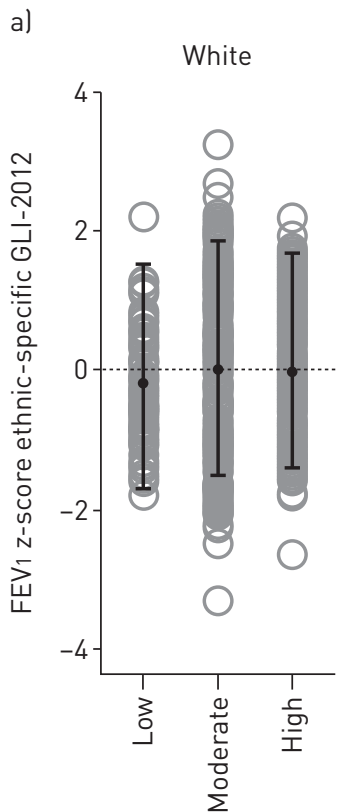

b)

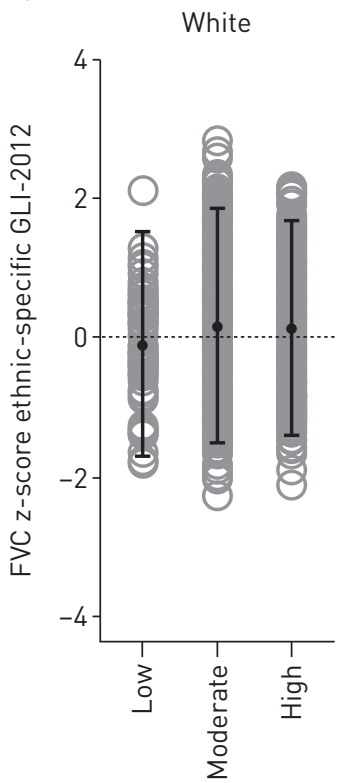

Black-African
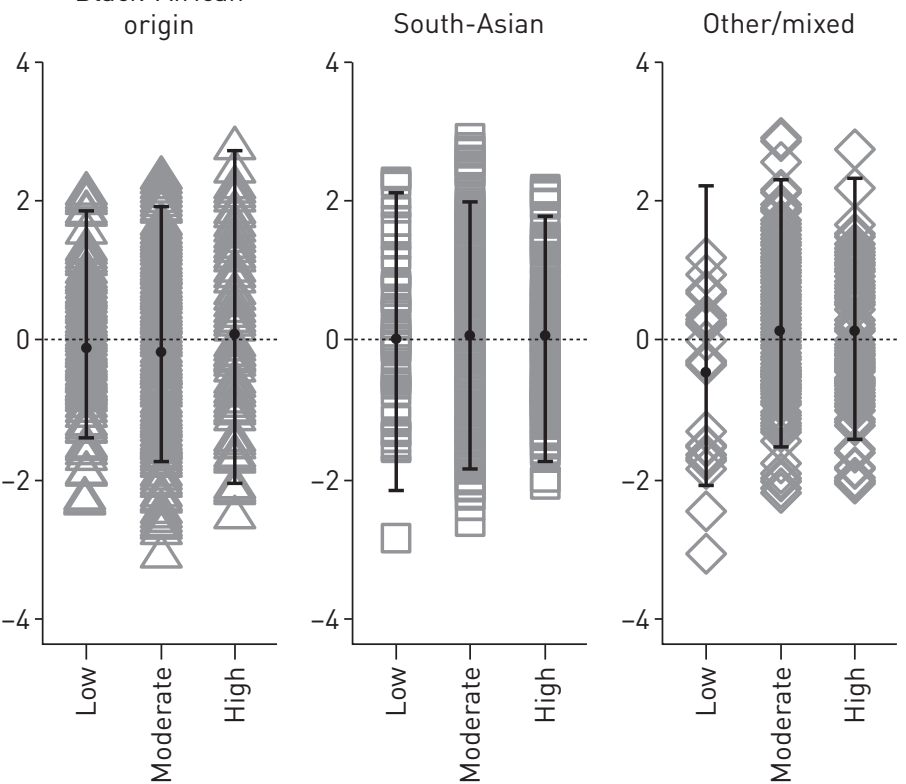

Categories of FAS

Black-African origin
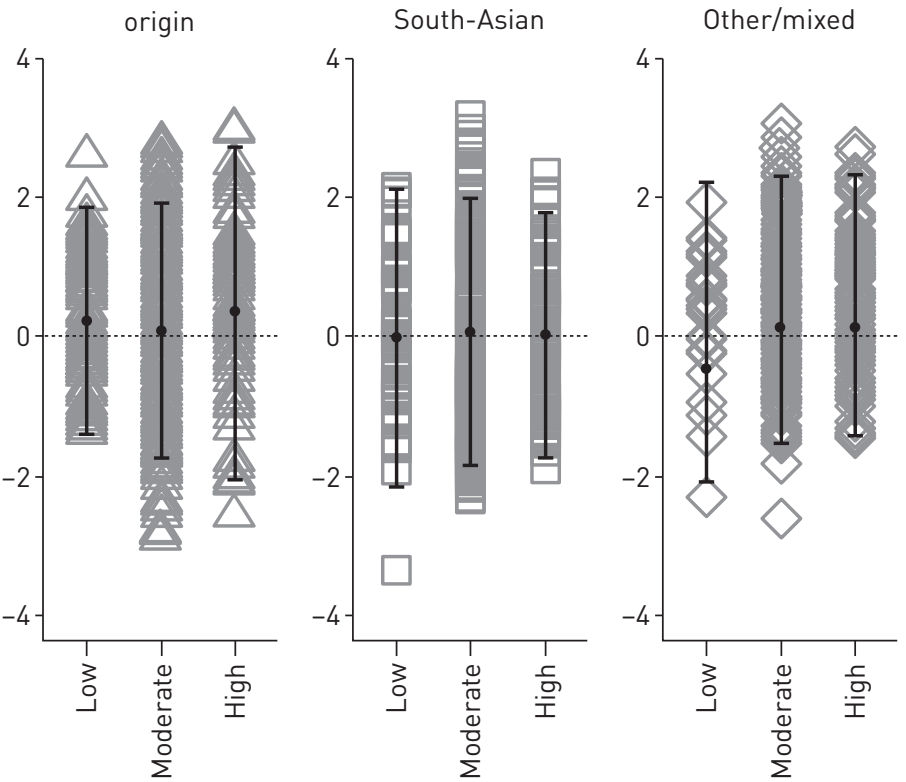

Categories of FAS

FIGURE 2 Associations between socioeconomic circumstances with lung function outcomes according to ethnicity: a) FEV1 and b) FVC. No differences in lung function between FAS categories were evident in each ethnic group. Data are presented as individual subjects with a black dot and error bars to represent the mean \pm 2 sDS for each subgroup. FEV1: forced expiratory volume in $1 \mathrm{~s}$; FVC: forced vital capacity; GLI: Global Lung Function Initiative; FAS: Family Affluence Scale.

ethnicity based on grandparental origins and criteria used in the UK national census addressed genetic, environmental and cultural sources of variability. However, their respective contributions to phenotype cannot be investigated until funding becomes available to analyse DNA samples collected as part of this study to investigate associations between genotype and lung function.

\section{Impact of body physique on ethnic differences in lung function}

Compared with White children, ethnic differences in lung function z-scores between Black-African origin and Other/mixed ethnicity children were similar in magnitude to those in the GLI-2012 reference, while 
TABLE 4 Forced expiratory volume 1 s (FEV1) and forced vital capacity (FVC) z-scores (Global Lung Function Initiative (GLI)-White) by ethnicity relative to White subjects, adjusted for socioeconomic indices for 2547 occasions with full anthropometric data and Family Affluence Scale (FAS)

Adjusted for age, sex, height, sitting height and chest width
Further adjusted for FAS

$\begin{array}{lcc}\text { FEV } 1 \text { z-score } & & \\ \text { Black-African origin } & -1.17(-1.3--1.1) & -1.16(-1.3--1.0) \\ \text { South-Asian } & -0.74(-0.8--0.6) & -0.73(-0.8--0.6) \\ \text { Other/mixed } & -0.45(-0.6--0.3) & -0.45(-0.6--0.3) \\ \text { BIC; df } & 5668 ; 11 & 5680 ; 13 \\ \text { FVC z-score } & & \\ \text { Black-African origin } & -1.11(-1.2--1.0) & -1.09(-1.2--1.0) \\ \text { South-Asian } & -0.77(-0.9--0.7) & -0.77(-0.9--0.7) \\ \text { Other/mixed } & -0.43(-0.6--0.3) & -0.43(-0.6--0.3) \\ \text { BIC; df } & 5495 ; 11 & 5508 ; 13\end{array}$

Data presented as $\beta$-coefficient $(95 \% \mathrm{CI})$, unless otherwise stated. BIC: Bayesian information criterion, $\mathrm{df}$ : degrees of freedom.

data from South-Asian children were similar to those for South-East Asians [7] and middle-class Bangalore children [10]. Of the numerous additional anthropometric measurements undertaken to quantify body physique, only sitting height and chest width significantly predicted spirometric lung function. Relatively longer legs (i.e. shorter trunk) naturally predict a smaller chest and lung volume for given standing height. Although these findings match those of the DASH (Determinants of Adolescent Social well-being and Health) study of multiethnic London adolescents [4], others report minimal impact of chest dimensions among South-Asian children [3]. Our weak association of chest shape with lung function was surprising, but may reflect the fact that growth in young children occurs primarily in the long bones (i.e. legs), with the trunkal growth spurt occurring later in puberty $[35,36]$. Growth rate differs by sex before and during puberty [27] with varying timing of pubertal maturation between ethnicities. Furthermore, some factors affecting chest size, such as diaphragmatic position or muscle strength, cannot be assessed by anthropometry. Although there is preliminary evidence of ethnic differences in residual volume/total lung capacity in children [37], it was not feasible to undertake plethysmographic assessments within our large, school-based study.

\section{Impact of socioeconomic circumstances and tobacco exposure}

Although socioeconomic circumstances and lung function are associated [4, 12], adjusting for body size (specifically sitting height) reduces the contribution of socioeconomic circumstances to ethnic variability $[1,4]$. While we cannot exclude the potential contribution of unmeasured social and environmental factors, across a wide range of socioeconomic circumstances, its association with lung function in this study was minimal and statistically insignificant (as also found in a longitudinal study of urban adults [38]). This is in marked contrast to our recent study in India using identical equipment and techniques [10] where, after adjusting for known confounders, average FEV1 and FVC in urban Indian children were similar to UK-Indian children, but significantly higher than in semi-urban and rural Indian children (by $\sim 6 \%$ and $\sim 11 \%$, respectively). These findings probably reflect marked differences in the degree of social deprivation between UK and India $[10,12]$ and suggest that there may be a threshold effect of poverty.

White and Other/mixed ethnicity children were most exposed to passive smoking, but in contrast to previous reports [39] we found no association of lung function with maternal smoking either in pregnancy or currently. Exposure may have been under-reported due to recall bias or social stigma, but overall the children's salivary cotinine levels were very low.

\section{Relevance in clinical practice}

As reported previously [8], results from this study verify the validity of the GLI ethnic-specific equations, which proved to be generally appropriate for London schoolchildren. The slightly poorer fit to the Other/ mixed group was not unexpected, given the relatively small numbers and heterogeneous nature of this group. Although there were only very small offsets for mean FEV1 and FVC z-scores among Black-African origin children, these were in opposite directions, such that mean FEV1/FVC was $0.54 \mathrm{z}$-score units lower than predicted for this group. However, by setting the lower limit of normal at $-1.96 \mathrm{z}$-score units $(2.5$ th 
centile), rather than -1.64 (5th centile), as recommended for epidemiological studies such as this [7], the risk of overdiagnosis of airway obstruction in this group can be minimised.

\section{Future directions}

Results from this study and others indicate that further adjustment for sitting height improves lung function prediction. The GLI-2012 multiethnic equations fit many populations well $[8,40]$ and are currently the best option for use in multiethnic populations, but are based on standing height. When used in developed countries where lung function has been stable for $>40$ years [7], such an approach probably suffices. Given the generally excellent fit of our data to the GLI all-age reference ranges, the limited age range of the SLIC population, and the fact that accurate measurements of sitting height and chest width are unlikely to be recorded during routine clinical assessments, we have not presented any new equations based on the SLIC data, but instead recommend continued usage of the current GLI equations in both research and clinical practice. Despite their contribution to model fit and a relative narrowing of confidence intervals, inclusion of sitting height and/or chest width made minimal impact to predicted median values based on data from London schoolchildren (see online supplementary figure E5 for details). However, to take account of secular changes in body proportions in developing countries, sitting height could usefully be included in future assessments. Inclusion of chest measurements within a clinical scenario may be less practical.

\section{Conclusion}

After adjustment for sex, age and height, ethnic differences in spirometry are reduced by further adjustment for sitting height. However, ethnic differences persist despite adjusting for a wide range of potential determinants, including body physique and socioeconomic circumstances. Use of the GLI-2012 multiethnic equations largely overcomes such differences in London schoolchildren, demonstrating their validity and relevance in current clinical practice.

\section{Acknowledgements}

We would particularly like to thank the head teachers and staff of participating schools for facilitating the recruitment and school assessments, and in particular the children and families who participated in this study.

\section{References}

1 Harik-Khan RI, Muller DC, Wise RA. Racial difference in lung function in African-American and White children: effect of anthropometric, socioeconomic, nutritional, and environmental factors. Am J Epidemiol 2004; 160: 893-900.

2 Pellegrino R, Viegi G, Brusasco V, et al. Interpretative strategies for lung function tests. Eur Respir J 2005; 26 : 948-968.

3 Whittaker AL, Sutton AJ, Beardsmore CS. Are ethnic differences in lung function explained by chest size? Arch Dis Child Fetal Neonatal Ed 2005; 90: F423-F428.

4 Whitrow MJ, Harding S. Ethnic differences in adolescent lung function: anthropometric, socioeconomic, and psychosocial factors. Am J Respir Crit Care Med 2008; 177: 1262-1267.

5 Kumar R, Seibold MA, Aldrich MC, et al. Genetic ancestry in lung-function predictions. N Engl J Med 2010; 363: $321-330$.

6 Stanojevic S, Wade A, Stocks J. Reference values for lung function: past, present and future. Eur Respir J 2010; 36: $12-19$.

7 Quanjer PH, Stanojevic S, Cole TJ, et al. Multi-ethnic reference values for spirometry for the 3-95-yr age range: the global lung function 2012 equations. Eur Respir J 2012; 40: 1324-1343.

8 Bonner R, Lum S, Stocks J, et al. Applicability of the global lung function spirometry equations in contemporary multiethnic children. Am J Respir Crit Care Med 2013; 188: 515-516.

9 Kirkby J, Lum S, Stocks J, et al. Adaptation of the GLI-2012 spirometry reference equations for use in Indian children. Eur Respir J 2014; 44: Suppl. 58, 191.

10 Sonnappa S, Lum S, Kirkby J, et al. Disparities in pulmonary function in healthy children across the Indian urban-rural continuum. Am J Respir Crit Care Med 2015; 191: 79-86.

11 Wells JC, Ruto A, Treleaven P. Whole-body three-dimensional photonic scanning: a new technique for obesity research and clinical practice. Int J Obes (Lond) 2008; 32: 232-238.

12 Raju PS, Prasad KV, Ramana YV, et al. Influence of socioeconomic status on lung function and prediction equations in Indian children. Pediatr Pulmonol 2005; 39: 528-536.

13 Duong M, Islam S, Rangarajan S, et al. Global differences in lung function by region (PURE): an international, community-based prospective study. Lancet Respir Med 2013; 1: 599-609.

14 Burney P, Hooper R. The use of ethnically specific norms for ventilatory function in African-American and white populations. Int J Epidemiol 2012; 41: 782-790.

15 Harik-Khan RI, Fleg JL, Muller DC, et al. The effect of anthropometric and socioeconomic factors on the racial difference in lung function. Am J Respir Crit Care Med 2001; 164: 1647-1654.

16 Brehm JM, Acosta-Perez E, Klei L, et al. African ancestry and lung function in Puerto Rican children. J Allergy Clin Immunol 2012; 129: 1484-1490.

17 Strippoli MP, Kuehni CE, Dogaru CM, et al. Etiology of ethnic differences in childhood spirometry. Pediatrics 2013; 131: e1842-e1849.

18 Lum S, Bountziouka V, Sonnappa S, et al. How "healthy" should children be when selecting reference samples for spirometry? Eur Respir J 2015; 45: 1576-1581. 

status in a multi-ethnic population of children: an observational study. NPJ Prim Care Respir Med 2015; 25 : 14112.

20 Lum S, Bountziouka V, Harding S, et al. Assessing pubertal status in multi-ethnic primary schoolchildren. Acta Paediatrica 2015; 104: e45-e48.

21 Wells JC, Stocks J, Bonner R, et al. Acceptability, precision and accuracy of 3D photonic scanning for measurement of body shape in a multi-ethnic sample of children aged 5-11 years: the SLIC study. PLoS One 2015; 10: e0124193.

22 Lee S, Bountziouka V, Lum S, et al. Ethnic variability in body size, proportions and composition in children aged 5 to 11 years: is ethnic-specific calibration of bioelectrical impedance required? PLoS One 2014; 9: 1-17.

23 Lum S, Sonnappa S, Wade A, et al. Exploring ethnic differences in lung function: the Size and Lung function In Children (SLIC) study protocol and feasibility, 2014. http://discovery.ucl.ac.uk/id/eprint/1417500. Date last accessed: August 10, 2015

24 Kirkby J, Welsh L, Lum S, et al. The EPICure study: comparison of pediatric spirometry in community and laboratory settings. Pediatr Pulmonol 2008; 43: 1233-1241.

25 Andersen A, Krolner R, Currie C, et al. High agreement on family affluence between children's and parents' reports: international study of 11-year-old children. J Epidemiol Community Health 2008; 62: 1092-1094.

26 Department for Communities and Local Government. English indices of deprivation 2010. https://www.gov.uk/ government/collections/english-indices-of-deprivation. Date last accessed: September 30, 2015.

27 Cole TJ, Freeman JV, Preece MA. British 1990 growth reference centiles for weight, height, body mass index and head circumference fitted by maximum penalized likelihood. Stat Med 1998; 17: 407-429.

28 Schwarz GE. Estimating the dimension of a model. Ann Statist 1978; 6: 461-464.

29 Pinheiro J, Bates D, DebRoy S, et al. R_Core_Team. nlme: linear and nonlinear mixed effects models. R package version 3.1-118, 2014. http://cran.r-project.org/web/packages/nlme/index.html. Date last accessed: August 19, 2015.

30 Jarvis MJ, Fidler J, Mindell J, et al. Assessing smoking status in children, adolescents and adults: cotinine cut-points revisited. Addiction 2008; 103: 1553-1561.

31 Simpson CR, Sheikh A. Trends in the epidemiology of asthma in England: a national study of 333,294 patients. J R Soc Med 2010; 103: 98-106.

32 Whitrow MJ, Harding S. Asthma in Black African, Black Caribbean and South-Asian adolescents in the MRC DASH study: a cross sectional analysis. BMC Pediatr 2010; 10: 18.

33 Jaspers M, de Meer G, Verhulst FC, et al. Limited validity of parental recall on pregnancy, birth, and early childhood at child age 10 years. J Clin Epidemiol 2010; 63: 185-191.

34 Catov JM, Newman AB, Kelsey SF, et al. Accuracy and reliability of maternal recall of infant birth weight among older women. Ann Epidemiol 2006; 16: 429-431.

35 Tanner JM. Growth at adolescence. 2nd Edn. Oxford, Blackwell Scientific Publications, 1962.

36 Cole TJ. Secular trends in growth. Proc Nutr Soc 2000; 59: 317-324.

37 Kirkby J, Bonner R, Lum S, et al. Interpretation of pediatric lung function: impact of ethnicity. Pediatr Pulmonol 2013; 48: 20-26.

38 Menezes AM, Wehrmeister FC, Hartwig FP, et al. African ancestry, lung function and the effect of genetics. Eur Respir J 2015; 45: 1582-1589.

39 Carlsen KH, Carlsen KC. Respiratory effects of tobacco smoking on infants and young children. Paediatric Respir Rev 2008; 9: 11-19.

40 Hall GL, Thompson BR, Stanojevic S, et al. The Global Lung Initiative 2012 reference values reflect contemporary Australasian spirometry. Respirology 2012; 17: 1150-1151. 